\title{
Journey through six property rights stories along the Pacific Rim ${ }^{1}$
}

Lawrence W.C. Lai

Department of Real Estate \& Construction

University of Hong Kong

\section{Preamble}

It is a great privilege and a big challenge for me to be given the chance to review six research papers collected under the auspices of property rights and urban development. The collection signifies the growing interest of researchers in planning and development and the significance of institutional arrangements in spatial matters. The geographical focus of the papers on cities along the Eastern Pacific Rim also sheds light on the great effects of globalization and trade liberalisation on regimes (Japan being the exception) that were formerly governed by central economic planning, but are now on the road to rapid economic development predicated on a process of reinstituting private property rights in land, which may be said to be adopting the concept of planning by contract that is predicated on the equivalent of leasehold land tenure (Lai 1995) in practice, if not also in propaganda.

\section{Research setting}

\footnotetext{
${ }^{1}$ The commentator is thankful to Professor Frank T Lorne for his advice and ideas in writing this short review. All faults are the commentators.
} 
Research on planning and development, as players in the field are aware of, is so diverse in terms of areas of interest and methodologies, and complicated by geographical and jurisdictional idiosyncrasies that hamper real academic dialogue among peers, is rare. A reader who wants evidence of this proposition may simply try to search for the debates, replies, and rejoinders in journals dwelling on any single theoretical proposition. Most so-called "debates" represented by research papers are the identifications of authors holding some preconceived opposite positions. In some cases, the competition can be purely imaginary due to the authors' own confusion, but more frequently, the competition is noncommunicative, as one typical behavior of competition is to ignore and dismiss a competitor as if s/he had never existed. "Debates" as such are, in fact, statements against the positions of others that appear to be different without actually engaging the other person. Practices by journal editors and referees often help constrain competition posed by works with unfamiliar paradigms or methods when they screen them out, sometimes using a language that conveys the message that they should not have existed at all. The absence of real debate, which benefits research students - especially future researchers - most, entails that essential definitions, concepts, and propositions are not subject to careful scrutiny, which leads to greater confusion in intellectual discourse.

In this light, the greatest value of the collection of papers in this special issue should be seen in terms of their propensity to generate genuine academic debate in the planning and development field over the basic question of the relationship 
between property rights or, more specifically, as the papers reveal institutional arrangements on the one hand and resource allocation in the land market on the other. This relationship can be logically postulated as being unidirectional with either: (a) the former as an exogenous, design, or policy variable, as captured by the so-called "corollary of the Coase Theorem" (Lai 2007) and is the position of Ronald Coase and Steven Cheung in most of their writings, or (b) the latter as the determining factor, as argued very early on by Mancur Olson and later Douglass North. It can also be postulated as (c) in which the two factors interact and are, hence, truly endogenous. While the truth is most likely to be (c), as it is "holistic" and "realistic," it is also the hardest to generalize or verify and structure into a falsifiable hypothesis. This was correctly pointed out by the special issue editor in her introduction.

Method (a) is the most fertile and, hitherto, the most fruitful area for empirical research. Institutional arrangements can be taken to refer to a certain policy or a set of observable de jure or de facto rules of ordering resource use.

Method (b) is worth trying, but it is not easy. How do property rights themselves change in response to, say, a change in the logic of a market economy, transaction costs, or technology? As a matter of public interest and logic, when technology permits, there is always a social gain in the form of a clearer and better delineation of property rights, which is not necessarily the same as promoting a more litigious society (which may well be the rent-seeking attempts of lawyers) as one would otherwise accept the irrational idea that ambiguity is better than clarity. In such a case, there would be no need 
for scientific inquiry. That regimes seem to prefer a more ambiguous system of property rights or resist a better delineation of property rights, including (a) using auctions and tenders to allocate government land in lieu of "grants" made by local officials; and (b) requiring the identities of parties to and cash considerations of property transactions to become registered public information open to the whole world is likely due to vested interests (the transaction costs of changing an entrenched system) rather than the transaction costs associated with culture or technology. Hong Kong's anticorruption law, a colonial innovation, has been so powerful and successful that even the UK dares not adopt it for home use. To overcome resistance, an equivalent to the Olson shocks may be necessary. The sentiment of the day, in the absence of major ideological competition or threats, is not one of drastic revolutions, but of stable transitions and the avoidance of strong reactions by interest groups.

Placing the greatest value on the testability or falsifiablility of hypotheses (which entail predictability as well) and avoiding ambiguity in defining "property rights" in his property rights research, Cheung, commencing with his work, "The Contractual Nature of the Firm" (1983), limited his focus to the effects of changes in "contractual arrangements" 2 upon resource allocation in the examination of economic development in China.

The value of a case study approach based on careful observation and data gathering is most useful for refuting or qualifying existing theories and, hence, help a researcher avoid

${ }^{2}$ Meeting with Cheung in Shenzhen 25 February 2010 
the danger of allowing his/her work to degenerate into an adhoc report of facts with little general theoretical or practical policy value. As far as a narrative of institutional arrangements for a case study on land development is concerned, the need to specify clearly the changes from one set to another and produce evidence of corresponding adjustments in resource use patterns is essential if these changes are to be decisively important. To avoid falling into the trap of wrongly attributing events that come afterwards to events that happen earlier, there is a need to set test conditions and be mindful of counter examples.

In economics, many so-called new discoveries can be mere accidents that happened elsewhere, but were unreported or reported under other tiles or tackled from a different angle. In this light, the better theory is one that is more general and can better organise facts of apparently little connectivity for meaningful action or judgment, if not also prediction.

\section{The highest common factor}

Common to all works collected in this special issue is an enthusiastic concern with the question of property rights in the sense of institutional arrangements and their intimate relationship with land resource use in planning and development. Five articles in the issue use a case study approach. From them, some useful general propositions about the polities under investigation for validation in future informed debates can be found. The most general and important of these that I have found are: 
(1) Public opinion expressed through state controlled media and bodies affect policies regarding compensation, as well as land development (Kim);

(2) Unauthorised development attracts a betterment value settling compensation disputes (Webster et al.);

(3) The choice of litigation versus mediation depends on whether it takes (resumption) or re-allocates land (Whiting);

(4) A clearer delineation of property rights constrains corruption (Po) - a view that has a different emphasis from the work of (Abramson), which holds that informal rules are as important, if not more important, than formal laws and policies.

(5) The central government (of Japan) sidesteps local government objections to higher density development by using entrenched laws with incremental administrative devises (Sorensen).

These propositions echo many interesting real life examples elsewhere and articulate well with "received theories" in neoinstitutional economics. Prior to the introduction of a degree of representative democracy, the colonial government of Hong Kong, which held itself out to be "government by consent and consultation," respected freedom of the press and even used its own TV and radio programs to allow the public to vent their grievances. In China, public opinion (called "people's opinion") - insofar that it contains no ill motivations, written and published, connected to "foreign forces," or organized outside the control of the central government and, hence, treated as sectoral - carries a lot of weight in the country's 
modernized democratic centralism. "Might makes right" whether such a might is one of voice (Kim) or posed by numbers (Webster). The works of Kim and Webster should, therefore, inspire further theoretical work similar to that done at the level of a country's political economy beyond land development in the tradition of Umbeck (1991) and others, who have written on the subject of constitutional government during the time of a gold rush.

In spite of differences in the legal system and jurisprudence, the systematic choice of modes of dispute resolutions in China is definitely another good example of the application of the school of thought centred on the Economic Analysis of Law by Richard Posner $(1992,1993)$, which hinges on transaction cost considerations. The confident judgement based on one case study that stated that a clearer delineation of property rights effectively constrains corruption as a covert transaction is an edict of faith in the analysis of one of some earlier writings on the subject, for instance "A Theory of Price Control" by Cheung (1974) - one of his best, which is a treatise on resource use implications of changes in property rights arrangements.

The major contribution of Sorensen was to provide a good real world case, often absent from academic discussion, of a central government seeking to capitalize on "development pressures" by bypassing the restrictive laws captured by local governments in defeating intensifications of land use through administrative codes. A parallel can be drawn between this practice by the introduction into the UK planning legislation of the route of appeal to the Minister to bypass the restrictions imposed by local councils or the adoption by Hong Kong's 
colonial administrators to adopt the 999-year term for leasehold interests to circumvent the Foreign Office's directive against granting freehold interests in Hong Kong. The question of apparent haphazardness in the transaction cost implications of changes in institutional arrangements can be informed by a differentiation between movements along a given cost function and shifts in the whole function, as expounded by Lorne (2009).

It is true that nothing is new under the sun, but the reflections and shades may look different at different times in different places. These are often very beautiful and pleasing. The articles in this special issue reaffirm some of the past findings and provide new angles for future debate.

There is one thing that the commentator was keen to look for among the scholarly works on China and Vietnam: what exactly was the document or vehicle that proved titles for the "owners" of proprietary interests in rural land in these nominally socialist countries? Under common law regimes, "compensation" is a technical term related to "taking" in the case of a freehold or "resumption" in the case of leasehold rights. The point is that the theoretical generalization of property rights matters within common law jurisdictions, which could be very much different from those within a socialist regime. In this context, before going into details with the six papers individually, the author would like to share with reader an insightful comparative statement by Steven Cheung about de facto property rights in action and effect on the economy. "In the West, what the government expressly permits by law may in practice be not allowed whereas what is expressly disallowed is really prohibited. In China, what the 
law or policy permits is truly permitted but what is expressly banned can be rendered permissible."

\section{Individual characteristics}

The polemic work by Sorensen spurs readers to seek the answer to how a "medium range" path-dependent approach precisely differs from the reduction in transaction costs evolutionary thesis of Webster and Lai (2003) and the simple economic rationale of a change in value (measure by relative prices) of North (1990). The excitement is due to two concerns. First is the delimitation of the span of long, medium, and short terms. Second is how exactly one can show that the said approaches are mutually exclusive and inclusive so as to be able to draw a truly distinct conclusion about their compatibility or otherwise. High rise buildings spring up here and there in major and smaller cities in Asia. What is the prime mover behind the intensification of land use in Tokyo to drive things along 'the path' there from any other 'path' elsewhere? Path dependency is basically an 'evolutionary' concept that puts stress on inertia in institutions (see for instance Kasper and Streit 1998: 38, 391-392). An explanation of why a certain path is taken (say the driving force for changes along the path) is as significant as a description of what is happening along a path. In the final analysis what exactly is (not) the path under investigation must be pointed out. Besides, the work also calls for attention to be paid to definitional matters as "property rights," which are sometimes taken to refer to the entire de facto institution or system of property rights, in which case it should encompass the planning regulations and administrative measures. But at other times, it refers narrowly to mean de 
jure private property rights. Having said so, one must appreciate the great contribution of this work towards enriching the rare English literature on development controls in Japan.

The grassroots paper by Po also called for exactitude in concepts. The expression "common property," in the tradition of Hardin, Alchian, Demsetz, and Cheung, referred to completely non-exclusive resources (with the classic example being the oceans), whereas the initial property rights regime, under reform in this detailed case analysis, was more appropriately described as "communal property rights" (Lai 2007). Whether Ostrom's thesis theoretically really fitted the initial or the reformed property rights regime is a point that should attract further and better analysis.

The work of Abramson concluded with the bold assertion that "the clarification and individualization of property rights, as a legal project, has not shown itself to be a decisive force in Chinese urban spatial politics." Was this observation, which was reasonable insofar as evidence for it was adduced from a case analysis, uniquely Chinese or universal and ubiquitous due to the heavy transaction costs of using the court system, especially during a moment in which the law was rapidly developing? How secure were we to arrive at a broad statement that was not in tune with the observation of the grassroots paper of Po based on also one case study? 
The methodology presented in the works on land compensation by Whiting and by Webster and Zhao was sound and the arguments convincing. Both gave a precise and succinct factual and legal background to the negotiations over compensation. What one expected to capitalize on regarding the materials documented was the connectivity of the cases reviewed to the wider literature on the economic analysis of law along the transaction cost economics front, land adjustments along the development front, and/or the comparative literature along the legal front. A minor observation was that the real life example in Point 5 of the conclusion, embedded in Webster and Lai (2003) but not cited, was a small counter-factual example that replied to the general criticism of Sorensen in respect of neo-institutional inquiry.

Last, but not least, the work of Kim was very careful regarding its proper interpretation and theoretical limitations, and was a major innovation in property rights research because it not only provided a convincing case for the influence of "people's opinions" on their de facto rights, subject to a government that was not democratically represented in the Western sense, but also showed the usefulness of a content analysis of media data for property rights analysis. The decisiveness of opinion or moral suasion, while significant in the literature of communicative planning pioneered by Forrester and Healey based on the foundation of Habermas, had been neglected by 'mainstream' neo-institutional scholars. Barzel was known to have questioned the power of the Vatican in terms of the strength of its army - the Swiss Guards - in his explanation of 
the cost of protection in one of his books. But he paid no attention to the weight of the communications between the Pope and the U.S. President prior to the collapse of the Berlin Wall and, eventually, the USSR. A change in mindset was significant in promoting innovations important for sustainable development (Lai and Lorne 2003; Lorne 2009).

\section{Conclusion}

This collection was clearly a landmark in the research on the neo-institutional analysis of property rights. It straddled a geographical area of rapid development and self-conscious social and economic reforms and provided key references for future debate and ideas. It would surely attract other scholars from similar or competing perspectives to journey through these or other real life stories on property rights as a good method of understanding various aspects of rapid economic growth and development in what some Western scholars still prefer to describe as a "Confuscian" society.

\section{References}

ABRAMSON, D.B. (2010) Transitional property rights and local development history in China, Urban Studies, this issue.

CHEUNG, S.N.S. (1974) A theory of price control, Journal of Law and Economics, 17(1), pp. 53-71.

COASE, R.H. (1960) The problem of social cost, Journal of Law and Economics, 3(1), pp. 1-44. 
COASE, R.H. (1974) The lighthouse in economics, Journal of Law and Economics, 17(2), pp. 357-376.

KASPER, W. and STREIT, M.E. (1998), Institutional Economics, Cheltenham: Edward Elgar.

KIM, A.M. (2010) Talking back: the role of narratives in Vietnam's recent land compensation changes. Urban Studies, this issue.

LAI, L.W.C. (1995) Some theoretical issues of land use rights reform in China, Land Use Policy, 12(4), pp. 281-289.

LAI, L.W.C. (1997) Property rights justifications for planning and a theory of zoning. Progress in Planning 48(3), pp. 161-245.

LAI, L.W.C. (2007) 'The problem of social cost': the Coase Theorem and externality explained: using simple diagrams and examples to illustrate the role of land use planning in tackling externalities, Town Planning Review, 78(3), pp. 335-368.

LAI, L.W.C. and LORNE, F.T. (2003) Implementing sustainable development: institutional features, in L.W.C. LAI and F.T. LORNE (eds.) Understanding and Implementing Sustainable Development, New York: Nova Science Publishers.

LORNE, F.T. (2009) Macro-entrepreneurship and sustainable Development: the need for innovative solutions for promoting win-win Interactions" Environment Economics and Policy Studies 10(2), pp. 69-85.

POSNER, R. (1992) Economic Analysis of Law. Boston: Little Brown. 
POSNER, R. (1993) The new institutional economics meets law and economics. Journal of Institutional and Theoretical Economics 149(1), pp.73-87.

WEBSTER, C. and Zhao, Y (2010). Land dispossession and enrichment in China's suburban villages, Urban Studies, this issue.

WHITING, S.H. (2010), Values in land: fiscal pressures, land disputes, and justice claims in rural and peri-urban China, Urban Studies, this issue.

PO, L (2010), property rights reforms and changing grassroots governance in China's urban-rural peripheries: the case of Changping Districts in Beijing, Urban Studies, this issue.

UMBECK, J. (1981), Might makes rights: a theory of the formation and initial distribution of property rights, Economic Inquiry, 19(1), pp. 38-59. 